\title{
SARS-CoV-2 Reverse Transcription-Polymerase Chain Reaction Positivity and Seroprevalence among Health Care Workers in a Referral Cancer Institute: A Cross-sectional Study
}

\author{
Abdel-Rahman Zekri ${ }^{1}$, Ola S. Ahmed ${ }^{1}$, Noha Asem², Sherief Musa ${ }^{3}$, Mohamed Ibrahem ${ }^{4 *}$, Hany K. Soliman ${ }^{1}$, \\ Mohammed M. Hafez ${ }^{1}$, Margrit S. Nessim ${ }^{1}$, Hatem Aboelkasem ${ }^{5}$, Abeer A. Bahnassy ${ }^{6}$ \\ ${ }^{1}$ Department of Cancer Biology, Virology and Immunology Unit, National Cancer Institute, Cairo University, Cairo, Egypt; \\ ${ }^{2}$ Department of Public Health and Community Medicine, Faculty of Medicine, Cairo University, Cairo, Egypt; ${ }^{3}$ Department \\ of Endemic Medicine, Faculty of Medicine, Cairo University, Cairo, Egypt; ${ }^{4}$ Department of Medical Biochemistry, Faculty of \\ Medicine, Cairo University, Cairo, Egypt; ${ }^{5}$ Department of Surgery, National Cancer Institute, Cairo University, Cairo, Egypt; \\ ${ }^{6}$ Department of Pathology, National Cancer Institute, Cairo University, Cairo, Egypt
}

Edited by: Ksenija Bogoeva-Kostovska Citation: Zekri AR, Ahmed OS, Asem N, Musa S, Ibrahe M, Soliman HK, Hafez MM, Nessim MS, Aboelkasem Polymerase Chain Reaction Positivity and Seroprevatence among Health Care Workers in a Referral Cancer Institute: among Health Care Workers in a Referral Cancer Institute:
A Cross-sectional Study. Open Access Maced J Med Sci. 2022 Feb 03; 10(B):339-345 https://doi.org/10.3889/oamjms.2022.806 Keywords: Severe acute respiratory syndrome coronavirus 2; Coronavirus disease 2019; Healthcare workers; Cancer *Correspondence: Mohamed lbrahem, Departmen of Medical Biochemistry, Faculty of Medicine, Cairo University, Cairo, Egyp Received: 24-Nov-202 Revised: 21-Jan-2022 Accepted: 24-Jan-2022 Copyright: ๑ 2022 Abdel-Rahman Zekri, Ola S. Ahmed Noha Asem, Sherief Musa, Mohamed Ibrahem, Hany K. Soliman, Mohammed M. Hafez, Margrit S. Nessim, Hatem Aboelkasem Abeer A. Bahnassy
Funding: This research did not receive any financial Competing Interests: The authors have declared that no competing interests exis Open Access: This is an open-access article distribute under the terms of the Creative Commons Attribution-
NonCommercial 4.0 International License (CC BY-NC 4.0)

\begin{abstract}
BACKGROUND: During the ongoing coronavirus disease 2019 pandemic, healthcare workers (HCWs) are presumed to be at increased risk of infection by severe acute respiratory syndrome coronavirus 2 (SARS-CoV-2), transmitting the infection to vulnerable patients if they are not timeously isolated.

AIM: This study aimed to determine the point prevalence of SARS-CoV-2 infection in a cohort of HCWs providing oncology services

METHODS AND RESULTS: HCWs in a large referral cancer hospital in Egypt were tested using real-time reverse transcription-polymerase chain reaction (RT-PCR) on nasopharyngeal swabs, and immunochromatography-based rapid serological test (RST). Clinical and epidemiological data were collected. In 2020, $999 \mathrm{HCWs}$ were screened of whom 86 tested positive for SARS-CoV-2 by RT-PCR $(8.6 \%)$ and 127 subjects were seropositive for antibodies against SARS-CoV-2 by RST (12.8\%). Immunoglobulin M seroprevalence demonstrated considerable concordance with RT-PCR positivity (sensitivity $82.14 \%$ and specificity $96.71 \%$ ). Most HCWs ( $>95 \%$ ) reported adherence to personal protective equipment. Patient transporters/cleaner were the group with the highest frequency of positive RT-PCR $(19 \%)$ whereas laboratory and radiology technicians displayed the lowest frequency. Fever, dry cough, rhinorrhea, shortness of breath, fatigue and diarrhea were significantly associated with RT-PCR positivity, with increased likelihood of being positive with the presence of five or six simultaneous symptoms.

CONCLUSIONS: The point prevalence of SARS-CoV-2 infection in screened HCWs is $8.6 \%$ by RT-PCR and seroprevalence is $12.8 \%$ by RST. Strict measures should be implemented to minimize transmission within healthcare settings and to the community. Our data support the importance of HCWs screening for SARS-CoV-2, taking in account the significant proportion of asymptomatic carriers.
\end{abstract}

\section{Introduction}

Severe acute respiratory syndrome coronavirus 2 (SARS-CoV-2), resulting in coronavirus disease 2019 (COVID-19), has posed major challenges to healthcare systems globally [1], as well as, locally with the first laboratory confirmed case of COVID-19 in Egypt declared on February 14, 2020 [2]. Healthcare workers (HCWs) worldwide have been on the frontlines fighting this pandemic, accounting for a substantial proportion of COVID-19 cases [3]. A study of more than 72,000 patients with COVID-19 by the Chinese Centre for Disease Control and Prevention showed that by early February around $3000 \mathrm{HCWs}$ had become infected, accounting for $3.8 \%$ of all cases of COVID-19 [4]. In Europe, HCWs accounted for $8 \%$ of total cases in
Italy in early March [5] rising to $10.5 \%$ in late April [6], whereas, $26 \%$ of confirmed COVID-19 infections in Spain, were HCWs [7]. As of April 9, a total of 9282 HCWs in the U.S. were confirmed to have COVID-19, as reported to the Centers for Disease Control [8]. Understanding risk factors of SARS-CoV-2 infection in $\mathrm{HCWs}$ is of utmost importance, as it helps policymakers to formulate appropriate infection control measures in the hospital setting [9].

The unprecedented burden of COVID-19 has important implications for cancer care [10]. Given the extrinsic factors of the current pandemic (e.g., high morbidity/mortality and resource constraints) and the intrinsic factors of patients with cancer (e.g., highly vulnerable population, immunosuppressed state caused by the cancer itself or its treatment), HCWs in cancer facilities face great responsibilities to navigate the 
COVID-19 health crisis [11]. Oncology often requires a complex set of clinic visits, laboratory blood draws, imaging studies, infusion sessions, radiation therapy appointments and hospital admissions. Collectively, caring for patients with cancer requires numerous contact points, with resultant potential opportunities for SARSCoV-2 transmission [12]. Major oncology societies have issued recommendations to guide $\mathrm{HCW}$ s on the proper measures to sustain timely, appropriate health services to cancer patients while protecting themselves from becoming infected with SARS-CoV-2 [13].

Although, several papers describe prevalence and outcomes of COVID-19 in patients with cancer, there is a paucity of studies describing its impact on HCWs providing services to this vulnerable group of patients. This study was conducted to determine the extent of SARS-CoV-2 infection by real-time reverse transcription polymerase chain reaction (RT-PCR) and an immunochromatography based rapid serological test (RST) among HCWs providing oncology services.

\section{Subjects and Methods}

This study was approved by the Research Ethics Committee of the National Cancer Institute ( $\mathrm{NCl}$ ). Informed consent was obtained from all HCWs for data collection and SARS-CoV-2 testing. Participants reported demographic and medical history, exposure to a patient or another co-worker with suspected or confirmed SARSCoV-2 infection, in addition to symptoms compatible with COVID-19 in the 14 days preceding SARS-CoV-2 testing. Nasopharyngeal swabs on a viral transport media and whole blood samples collected from participants were sent to the virology and immunology unit, cancer biology department, $\mathrm{NCl}$ to detect SARS-CoV-2 RNA using real-time RT-PCR and anti-SARS-CoV-2 immunoglobulin $\mathrm{M}(\lg \mathrm{M})$ and $\lg \mathrm{G}$ antibodies using RST.

\section{SARS-CoV-2 RST}

Igs were detected by COVID-19 rapid IgM-IgG combined antibody test (BioMedomics Laboratories, North Carolina, USA). This is a lateral flow immunoassay used to detect anti-SARS-CoV-2 $\lg \mathrm{M}$ and IgG antibodies in human serum, plasma, or whole blood in vitro. $50 \mathrm{ul}$ of whole blood and $100 \mathrm{ul}$ of buffer were added to sample well and the results were read after 10 min, with a $96.7 \%$ sensitivity and a $97.1 \%$ specificity as reported by the manufacturer.

Detection of SARS-CoV-2 RNA in nasopharyngeal swabs

The genesig real-time PCR COVID-19 CE IVD (Genesig kit, primer design, United Kingdom) is intended to be used to achieve qualitative detection of COVID-19 viral RNA extracted from nasopharyngeal swabs, oropharyngeal swabs using applied Biosystems 7500 fast. For detection of SARS-CoV2 RNA, a total of 250-300 $\mu \mathrm{L}$ of each nasopharyngeal swab sample was used for viral RNA extraction using the QIAMP VIRAL RNA mini kit (Qiagen, Hilden, Germany) with an internal PCR control according to the manufacturer's instructions. The extracted viral RNA was used directly for amplification using Genesig real-time PCR Detection Kit using two primers/probe. One primer and TaqMan probe labeled at the 5'-end with the reporter molecule 6-carboxyfluorescein (FAM) for SARS-Cov-2 detection and the other primer/probe for internal extraction control detection labeled at the 5'-end with the reporter molecule Hexachloro-fluorescein for the test validation.

\section{Statistical analysis}

Categorical variables were expressed as numbers and percentages. Continuous variables were described as mean \pm standard deviation (SD). Chi-square testing was done as appropriate for comparison of features between positive and negative groups. $p<0.05$ was considered statistically significant. The sensitivity, specificity, positive predictive value (PPV), and negative predictive value (NPV) were calculated, along with the $95 \%$ confidence interval $(\mathrm{Cl})$.

\section{Results}

A total of $999 \mathrm{HCW}$ were enrolled in the study. The mean age of participants was $37.79 \pm 8.87$ and $52.6 \%$ were females. Around half of the screened HCWs (52.3\%) were administrative employees, $22 \%$ were nurses and $10.2 \%$ were physicians. Exposure to suspected or confirmed COVID-19 cases in the preceeding 2 weeks was reported by 136 participants (13.6\%), whereas, only four HCWs $(0.4 \%)$ reported travel during the preceding month.

Overall, $86 \mathrm{HCW}$ tested positive for SARSCoV-2 by RT-PCR (8.6\%). The characteristics of these individuals are summarized in Table 1. The age, sex, travel history, smoking habits and co-morbidities except diabetes, did not show any significant association with RT-PCR positivity to SARS-CoV-2. The proportion of positive RT-PCR ranged from 19\% (16/84) among patient transporters/cleaners to $11.4 \%$ (25/220) among nurses, $7.6 \%$ (40/522) among administrative employees and $3.9 \%$ (4/102) among physicians with minimal frequencies among laboratory and radiology technicians (1/52 and 0/19 respectively). Approximately, 44.2\% of the positive RT-PCR individuals reported exposure to COVID-19 cases in the preceeding 2 weeks. Most 
participants (>95\%), even in RT-PCR positive group, confirmed that they adhered to personal protective equipment (PPE), by wearing masks as recommended. Meanwhile, a total of 127 subjects were seropositive for antibodies against SARS-CoV-2 by RST (12.8\%). Of those, 91 were positive for IgM only $(9.1 \%), 28$ were positive for IgG only $(2.8 \%)$, and 8 showed simultaneous $\lg M$ and $\lg G$ positivity $(0.8 \%)$.

Table 1: Demographic, epidemiological and clinical characteristics of total healthcare workers screened for SARS-CoV-2, including individuals with positive RT-PCR test

\begin{tabular}{|c|c|c|c|c|c|c|c|}
\hline \multirow[t]{2}{*}{ Characteristic } & \multicolumn{2}{|l|}{ Total } & \multicolumn{2}{|c|}{ Negative PCR } & \multicolumn{2}{|c|}{$\begin{array}{l}\text { Positive PCR } \\
(\mathrm{n}=86)\end{array}$} & \multirow[t]{2}{*}{$p$-value ${ }^{\star *}$} \\
\hline & $\mathrm{n}( \pm)^{*}$ & $\%$ & $\mathrm{n}( \pm)$ & $\%$ & $\mathrm{n}$ & $\%$ & \\
\hline $\begin{array}{l}\text { Age (years), } \\
\text { mean } \pm S D\end{array}$ & \multicolumn{2}{|c|}{$37.79 \pm 8.87$} & \multicolumn{2}{|c|}{$37.70 \pm 8.91$} & \multicolumn{2}{|c|}{$38.76 \pm 8.51$} & 0.29 \\
\hline \multicolumn{8}{|l|}{ Gender } \\
\hline Male & 474 & 47.4 & 436 & 47.8 & 38 & 44.2 & 0.53 \\
\hline Female & 525 & 52.6 & 477 & 52.2 & 48 & 55.8 & \\
\hline \multicolumn{8}{|l|}{ Smoking } \\
\hline Current & 115 & 11.6 & 105 & 11.6 & 10 & 11.6 & 0.13 \\
\hline Former & 12 & 1.2 & 9 & 1.0 & 3 & 3.5 & \\
\hline No & 865 & 87.2 & 792 & 87.4 & 73 & 84.9 & \\
\hline Exposure to case & $136 / 859$ & 13.6 & $98 / 811$ & 10.8 & 38 & 44.2 & $<0.01$ \\
\hline Wearing mask & $968 / 31$ & 96.9 & $885 / 28$ & 96.9 & 83 & 96.5 & 0.83 \\
\hline Travel history & $4 / 959$ & 0.4 & $4 / 873$ & 0.5 & 0 & 0.0 & 0.53 \\
\hline \multicolumn{8}{|l|}{ Occupation } \\
\hline Physician & 102 & 10.2 & 98 & 10.7 & 4 & 4.7 & $<0.01$ \\
\hline Nurse & 220 & 22 & 195 & 21.4 & 25 & 29.1 & \\
\hline Reception/ & 522 & 52.3 & 482 & 52.8 & 40 & 46.5 & \\
\hline \multicolumn{8}{|l|}{$\begin{array}{l}\text { Administrative } \\
\text { clerk }\end{array}$} \\
\hline $\begin{array}{l}\text { Laboratory } \\
\text { technician }\end{array}$ & 52 & 5.2 & 51 & 5.6 & 1 & 1.2 & \\
\hline $\begin{array}{l}\text { Radiology } \\
\text { technician }\end{array}$ & 19 & 1.9 & 19 & 2.1 & 0 & 0 & \\
\hline Patient & 84 & 8.4 & 68 & 7.4 & 16 & 18.6 & \\
\hline
\end{tabular}

transporter/

Cleaner

Co-morbidities

Asthma

COPD

Diabetes

Hypertension

Coronary heart

disease

Rheumatic heart

disease

Chronic liver

disease

Cancer

Immunod
Symptoms

Any symptom at

time of swab

Fever

Dry cough

Productive cough

Sore throat

Rhinorrhea

Headache

Dyspnoea

Myalgia/arthralgia

Diarrhea

Fatigue

Conjunctival

congestion

Number of positive versus negative, ${ }^{* *}$ From Chi-squared test, COPD: Chronic obstructive pulmonary disease, SARS-CoV-2: Severe acute respiratory syndrome coronavirus 2, RT-PCR: Reverse transcription-polymerase chain reaction.

Participants in this study were divided into two groups: those with positive RT-PCR $(n=70)$ findings for SARS-CoV-2 and those with negative RT-PCR $(n=79)$ results for SARS-CoV-2.

As shown in Figure 1, amongst the $86 \mathrm{HCWs}$ with RT-PCR positive samples, the RST detected 75 seropositive $(89.3 \%) \mathrm{HCWs}$, either to $\operatorname{IgM}(\mathrm{n}=61$, $72.6 \%), \lg G(n=6,7.1 \%)$ or both $(n=8,9.5 \%)$. On the contrary, only $5.7 \%$ of the subjects with negative RT-PCR were seropositive $(n=52)$. Performance

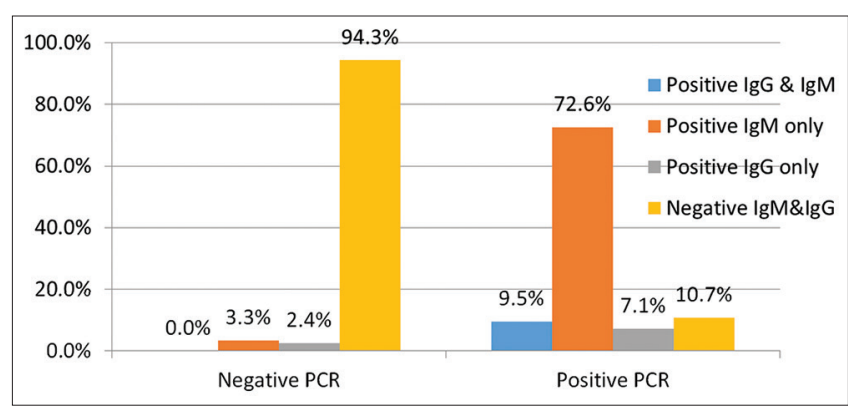

Figure 1: Seroprevalence of anti-severe acute respiratory syndrome coronavirus 2 immunoglobulin $M$ and immunoglobulin $G$ antibodies by rapid serological test in reverse transcription-polymerase chain reaction (RT-PCR)-positive and RT-PCR-negative healthcare workers

characteristics of RST compared to RT-PCR are shown in Table 2. In the current study, the sensitivity of IgM was $82.14 \%(95 \% \mathrm{Cl}: 72.26-89.65)$ and the specificity was $96.71 \%(95 \% \mathrm{Cl} 95.33-97.77)$. The PPV and the NPV of were $69.70 \%$ and $98.33 \%$, respectively. When calculated for IgG, the sensitivity became $16.67 \% \quad(95 \% \mathrm{Cl}: 9.42-26.38)$ and the specificity, PPV and NPV being $97.59 \% 38.89 \%$ and $92.70 \%$, respectively.

Table 2: Performance characteristics of rapid serological test in comparison to RT-PCR

\begin{tabular}{|c|c|c|c|c|c|c|}
\hline \multirow[t]{2}{*}{ Measure } & \multicolumn{2}{|c|}{$\lg M$ and/or IgG } & \multicolumn{2}{|l|}{$\operatorname{lgM}$} & \multicolumn{2}{|l|}{$\lg G$} \\
\hline & Value (\%) & $95 \mathrm{Cl}$ & Value (\%) & $95 \% \mathrm{Cl}$ & Value (\%) & $95 \% \mathrm{Cl}$ \\
\hline Sensitivity & 89.29 & $80.63-94.98$ & 82.14 & $72.26-89.65$ & 16.67 & $9.42-26.38$ \\
\hline Specificity & 94.29 & $92.58-95.71$ & 96.71 & $95.33-97.77$ & 97.59 & $96.37-98.48$ \\
\hline PPV & 59.06 & $52.30-65.48$ & 69.70 & $61.47-76.83$ & 38.89 & $25.28-54.48$ \\
\hline NPV & 98.96 & $98.09-99.44$ & 98.33 & $97.38-98.94$ & 92.70 & $92.02-93.33$ \\
\hline Accuracy & 93.87 & $92.19-95.28$ & 95.48 & $93.99-96.68$ & 90.75 & $88.78-92.48$ \\
\hline
\end{tabular}

Finally, the performance of VivaDiag COVID-19 $\mathrm{IgM} / \mathrm{lgG}$ Rapid Test LFIA was tested in 50 patients at their first access at emergency room department with fever and respiratory syndrome (34 M/16 F; median age, 61.50; range, 33-97 years) in comparison with results of nasal swab molecular screening.

The association between selected symptoms and RT-PCR results is shown in Table 1. Thirty three percent of participants $(n=331)$ reported symptoms concomitant with COVID-19 at the time of swab. Among those $\mathrm{HCWs}$, the frequency of positive molecular tests was $10.9 \%$, while among asymptomatic HCWs the frequency was slightly lower $(7.5 \%)$. Among the 86 RT-PCR positive subjects, 50/86 (58.1\%) were asymptomatic at the time of testing with RT-PCR, whereas, $36 \mathrm{HCWs}$ had at least one symptom associated with COVID-19 (41.9\%). SARS-CoV-2 positive HCWs reported several symptoms more frequently than those with negative assays: fever $(17.4 \%$ vs. $0.8 \%)$, rhinorrhea $(17.4 \%$ vs. $5.9 \%)$, dry cough $(16.3 \%$ vs. $6.6 \%)$, fatigue ( $14 \%$ vs. $4.6 \%)$, dyspnoea (12.8 vs. $4.1 \%)$ and diarrhoea ( $10.5 \%$ vs. $5 \%$ ). Total symptoms reported at time of swab ranged from 0 to 7 , with increased likelihood of being RT-PCR positive in case of presence of five or six simultaneous symptoms (Table 3 ). 
Table 3: Association between number of symptoms and proportion of RT-PCR positivity among healthcare workers tested for SARS-CoV-2

\begin{tabular}{lllll}
\hline Number of symptoms & Subjects & Positive test & $\%$ & $\mathrm{p}$-value* \\
\hline No symptoms & 668 & 50 & 7.5 & $<0.001$ \\
One symptom & 190 & 10 & 5.3 & \\
Two symptoms & 60 & 9 & 15 & \\
Three symptoms & 33 & 3 & 9.1 & \\
Four symptoms & 19 & 3 & 15.8 & \\
Five symptoms & 10 & 5 & 50 & \\
Six symptoms & 6 & 3 & 50 & \\
Seven symptoms & 12 & 3 & 25 & \\
"*From Chi-squared test, RT-PCR: Reverse transcription-polymerase chain reaction, SARS-CoV-2: Severe \\
acute respiratory syndrome coronavirus 2.
\end{tabular}

Finally, we observed a mean time from first positive RT-PCR test to a negative test being $2.83 \pm$ 1.68 days (Figure 2 ) with the majority of cases becoming negative within 2 days. However, 2/76 subjects were still positive 7 days after first positive test.

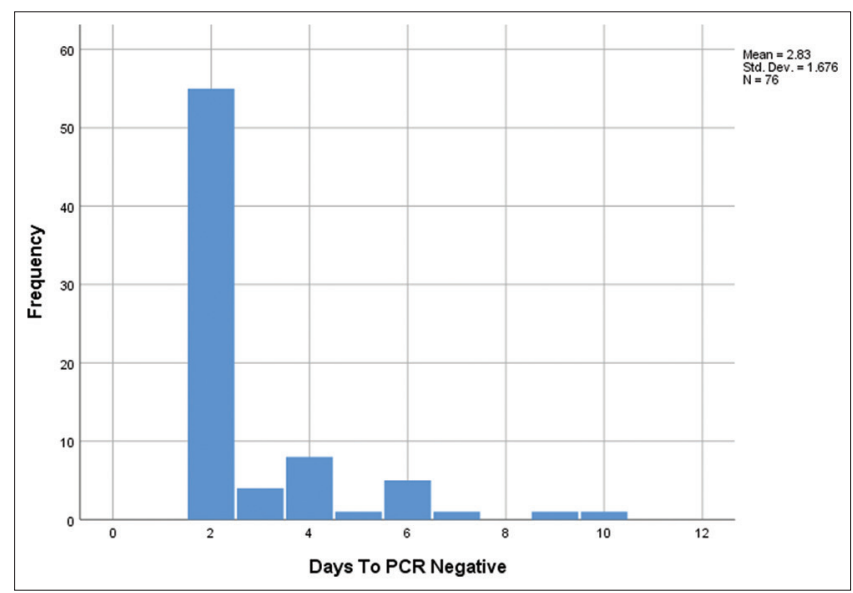

Figure 2: Duration to first negative test result among 76 reverse transcription-polymerase chain reaction positive healthcare workers

\section{Discussion}

HCWs have been hard-hit by the COVID-19 pandemic with several reports of resultant morbidity, posing a risk to vulnerable patients and fellow workers in addition to potential propagation of hospital-tocommunity transmission [14]. Previously, nosocomial outbreaks of SARS-CoV and Middle East respiratory syndrome coronavirus played an important role in their spread [15]. Nonetheless, characterization and quantification of healthcare personnel infected with SARS-CoV-2 are under-studied [16]. To our knowledge, this is the first study to describe the real-life situation of SARS-CoV-2 among HCWs in a large referral institute providing oncology services to the particularly vulnerable cancer patients.

In this study, a total of 86 SARS-CoV-2 cases were confirmed by positive RT-PCR ( $8.6 \%$ of screened HCWs). This proportion is comparable to the $6 \%$ described by Kluytmans-van den Bergh et al. in a Dutch cohort of $1353 \mathrm{HCWs}$ [17], and the $8.8 \%$ described by Lombardi et al. in an Italian cohort of $1573 \mathrm{HCWs}$ [18], whereas it is significantly lower than the $38 \%$ reported by Folgueira et al. in a Spanish cohort of 2085 HCWs [19].
Despite being the current standard to diagnose SARS-CoV-2 due to its high specificity, molecular testing via nucleic acid amplification has limitations such as relatively longer time and the need for laboratories with specific expertise [20]. It is also highly dependent on the timing and quality of respiratory sample collection with suboptimal sensitivity in some reports [21], [22].

Therefore, adding serological assays for the presence of antibodies against SARS-CoV-2 might allow better capture of the SARS-CoV-2 situation in a population, especially in epidemiological studies [23]. IgM antibodies are produced short term after infection, whereas IgG are produced in a more delayed timescale and are likely to persist for a longer time after viral clearance [24]. In our study, antibodies could be detected by RST in 127/999 HCWs (12.8\%), raising the number of HCWs with at least one positive test (RT-PCR and/ or RST) to 138 (13.8\% of screened HCWs). In a similar study in a tertiary reference hospital in Belgium, among 326 HCWs, 41 SARS-CoV-2 cases were confirmed by RT-PCR and/or serology representing an overall rate of $12.6 \%$ [23]. On the other hand, $525 \mathrm{HCWs}$ were screened for SARS-CoV-2 with a different RST in a cancer institute in Bari. Six subjects $(1.1 \%)$ resulted with positive IgM, none of whom had positive oropharyngeal swabs upon RT-PCR testing [25].

Advantages of immunochromatography based RST include ease of performance without specific laboratory equipment, simple interpretation, and rapid results [26]. However, its results should be interpreted cautiously until sufficiently validated to determine their reliability [20]. When compared to the reference method, the RST demonstrated substantial concordance with the RT-PCR. Of the $86 \mathrm{HCWs}$ who did test positive in the RT-PCR test, $82.1 \%$ were seropositive to IgM, and, most HCWs with negative RT-PCR were also negative for both IgG and IgM (94.3\%). The sensitivity of the IgM by RST was $82.14 \%$ and the specificity was $96.71 \%$.

For HCWs with discordant results of $\operatorname{lgM}$ detected by RST while negative at nasopharyngeal swabs $(3.3 \%$ in our study), the possibility of falsely positive RST or falsely negative nasopharyngeal swab should be considered, with the latter of epidemiological concern, as missed infections could further spread SARS-CoV-2 unnoticed.

IgG seroprevalence in our cohort was $19 \%$, but only $2.5 \%$ had negative concomitant RT-PCR. Negative results by RST are unreliable to exclude COVID-19 in acute-care settings because antibody production might be undetectable during the early phase of infection, limiting its sensitivity (as in our study) and underestimating the true prevalence rate of the disease [27]. Initial reports suggest that following infection with SARS-CoV-2, the immune system takes 6-21 days to produce $\lg M$ and IgG antibodies [28]. Therefore, follow-up of antibody titer changes over time might be required to estimate more accurate 
cumulative infection rates in HCWs. Importantly, the correlation between seropositivity and protection against reinfection, as well as the duration of protective immunity, remain to be clarified [16]. Therefore, even health personnel with anti-SARS-CoV-2 antibodies should adhere to PPE.

In our study, we found that SARS-CoV-2 acquisition was unrelated to sex or age. When stratified according to occupation, positive test frequencies were highest among subgroups not directly involved in clinical care (e.g. patient transporters/cleaners), which might be explained by lower perception of risk leading to less careful practices and higher risk of acquiring the infection. Consequently, screening of these personnel and increasing their awareness of proper infection control measures should be stressed. In our study, $44.2 \%$ of positive cases reported contact with suspected or confirmed cases. However, we cannot exclude un-recognized household exposure as an added source of infection among HCWs. During a pandemic, rates of SARS-CoV-2 infection among HCWs might rather reflect general community transmission than nosocomial exposure [19]. Consistent adherence to PPE is necessary to reduce SARS-CoV-2 transmission among HCWs [24]. In our study, the majority of HCWs (>95\%) confirmed adherence to mask. However, even with adequate PPE, HCWs remain at higher risk, highlighting the importance of additional risk mitigation strategies [29].

It is well-recognized that COVID-19 individuals with co-morbidities, have a worse prognosis [30]. However, only diabetes showed significant association with RT-PCR positivity to SARS-CoV-2 in our cohort. Previous studies have shown a relationship between hemoglobin $\mathrm{A} 1 \mathrm{C}$ and risk of hospital admission for respiratory tract infections [31]. However, diabetes does not seem to increase the risk of acquiring COVID-19 according to published literature, although diabetes is a risk factor for developing severe forms of COVID-19, emphasizing the importance of blood glucose monitoring and control [32]. On the contrary, HCWs with history of asthma in our study were siginificantly lower in SARS-CoV-2 positivity. Theoretically, asthmatic patients should have increased susceptibility and severity for SARS-CoV-2 infection due to a deficient antiviral immune response and the tendency for exacerbation by respiratory viruses [33]. However, existing studies show no clear evidence of this higher risk [34]. Certain aspects of type 2 immune response, including eosinophils and specific cytokines, in addition to anti-asthmatic drugs, might provide protective effects against COVID-19 by enhancing antiviral defense [33].

Thirty three percent of participants had at least one symptom associated with COVID-19 when tested with the swab. The frequency of positive RT-PCR among them $(10.9 \%)$ is $<18 \%$ and $24 \%$ frequencies reported by Keeley et al. and Lombardi et al. in 1533 and
503 symptomatic HCWs, respectively [18], [35]. In our cohort of HCWs, the individual symptoms significantly associated with positivity of nasopharyngeal swab for SARS-CoV-2 were fever, rhinorrhea, dry cough, fatigue, dyspnoea and diarrhoea. It is well established that fever along with respiratory symptoms represent the common symptoms of COVID-19 [36], but gastrointestinal symptoms, including diarrhoea have been increasingly documented in COVID-19 [37]. This should raise the index of suspicion when HCWs present with digestive symptoms rather than waiting for respiratory symptoms to emerge. Also, the likelihood of being RT-PCR positive increased with the presence of five or six simultaneous symptoms reported.

Although the World Health Organization advocates widespread testing for SARS-CoV-2 [38], national capacities differ considerably, restricting SARS-CoV-2 testing in most hospitals to HCWs who are symptomatic or have symptomatic household contacts. One of the strengths of our study was expanding SARS-CoV-2 screening to asymptomatic HCWs. It should be underlined that, despite the low relative frequency of positive RT-PCR among asymptomatic HCWs (7.5\%), their number was high in absolute terms $(n=50)$, meaning that more than half of those infected could be missed with a screening strategy based on symptoms only. Therefore, taking in consideration available resources, screening all HCWs irrespective of symptoms, seems to be the best approach to limit intrahospital spread [39].

Finally, we observed a mean time from first positive test to a negative test of 2.83 days, which is shorter than many published reports [18], [40]. The duration of viral replication and shedding has important implications in guiding isolation period after exposure to a confirmed case and the best time to re-perform a nasopharyngeal swab [41]. In some individuals, the RT-PCR can remain detectable for up to 6 weeks, however, in most of cases, they represent inactive genetic material without significant transmission [24].

\section{Conclusions}

In conclusions, the point prevalence of SARSCoV-2 infection in our cohort of HCWs in the cancer institute was $8.6 \%$ as determined by RT-PCR on nasopharnygeal swabs. Seroprevalence detected by RST was $12.8 \%$ with a substantial concordance of results. Our data illustrate the need for additional measures to reduce SARS-CoV-2 transmission in healthcare settings during the current pandemic, including screening of HCWs regardless of presence of COVID-19 symptoms 


\section{Compliance with Ethical Standards}

Informed consent was obtained from all individual participants included in the study.

\section{Availability of Data and Material}

Data is available upon request by reviewers but not to be published due to the Egyptian low of data security and privacy.

\section{References}

1. Del Rio C, Malani PN. 2019 novel Coronavirus-important information for clinicians. JAMA. 2020;323(11):1039-40. https:// doi.org/10.1001/jama.2020.1490

PMid:32022836

2. WHO, Coronavirus Disease 2019 (COVID-19) Situation Report-26; 2020. Available from: https://www.who.int/docs/ default-source/coronaviruse/situation-reports/20200215sitrep-26-covid-19.pdf?sfvrsn=a4cc6787_2 [Last accessed on 2020 Feb 15].

3. Kursumovic E, Lennane S, Cook TM. Deaths in healthcare workers due to COVID-19: The need for robust data and analysis. Anaesthesia. 2020;75(8):989-92. https://doi. org/10.1111/anae.15116

PMid:32397005

4. The Novel Coronavirus Pneumonia Emergency Response Epidermiology Team. The epidemiological characteristics of an outbreak of 2019 novel Coronavirus diseases (COVID-19)China, 2020. China CDC Weekly. 2020;2:113-22.

5. Sorveglianza Integrata COVID-19 in Italia. Instituto Superiore di Sanita; 2020. Available from: https://www.portale.fnomceo.it/ wp-content/uploads/2020/03/infografica_17marzo-ita.pdf [Last accessed on 2020 Apr 29].

6. Sorveglianza Integrata COVID-19. Instituto Superiore di Sanita; 2020. Available from: https://www.portale.fnomceo.it/ wp-content/uploads/2020/04/infografica_27aprile-ita.pdf [Last accessed on 2020 Apr 29].

7. European Centre for Disease Prevention and Control, Coronavirus Disease 2019 (COVID-19) in the EU/EEA and the UK-Eighth Update; 2020. Available from: https://www. ecdc.europa.eu/sitesdefault/files/documents/covid-19-rapidrisk-assessmentcoronavirus-disease-2019-eighth-update-8april-2020.pdf [Last accessed on 2020 Mar 05].

8. CDC COVID-19 Response Team. Characteristics of Health Care Personnel with COVID-19-United States, February 12-April 9, 2020. MMWR Morb Mortal Wkly Rep. 2020;69(15):477-81. https://doi.org/10.15585/mmwr. $\mathrm{mm} 6915 \mathrm{e} 6$

PMid:32298247

9. Chen Y, Tong X, Wang J, Huang W, Yin S, Huang R, et al. High SARS-CoV-2 antibody prevalence among healthcare workers exposed to COVID-19 patients. J Infect. 2020;81(3):420-6. https://doi.org/10.1016/j.jinf.2020.05.067

PMid:32504745
10. Richards M, Anderson M, Carter P, Ebert BL, Mossialos E. The impact of the COVID-19 pandemic on cancer care. Nat Cancer. 2020;1:565-7. https://doi.org/10.1038/s43018-020-0074-y PMid:32838302

11. Kamboj M and Sepkowitz K. Nosocomial infections in patients with cancer. Lancet Oncol. 2009;10(6):589-97. https://doi. org/10.1016/S1470-2045(09)70069-5

PMid:19482247

12. Alhalabi $O$, Subbiah V. Managing cancer care during the COVID19 pandemic and beyond. Trends Cancer. 2020;6(7):533-5. https://doi.org/10.1016/j.trecan.2020.04.005 PMid:32386875

13. Schrag D, Hershman DL, Basch E. Oncology practice during the COVID-19 pandemic. JAMA. 2020;323(20):2005-06. https://doi. org/10.1001/jama.2020.6236 PMid:32282023

14. Ng K, Poon BH, Kiat Puar TH, Quah JL, Loh WJ, Wong YJ, et al. COVID-19 and the risk to health care workers: A case report. Ann Intern Med. 2020;172(11):766-7. https://doi.org/10.7326/ L20-0175 PMid:32176257

15. Sikkema RS, Pas SD, Nieuwenhuijse DF, O'Toole Á, Verweij J, van der Linden $A$, et al. COVID-19 in health-care workers in three hospitals in the south of the Netherlands: A crosssectional study. Lancet Infect Dis 2020;20(11):1273-80. https:// doi.org/10.1016/S1473-3099(20)30527-2

PMid:32622380

16. Garcia-Basteiro AL, Moncunill G, Tortajada M, Vidal M, Guinovart C, Jiménez A, et al. Seroprevalence of antibodies against SARS-CoV-2 among health care workers in a large Spanish reference hospital. Nat Commun. 2020;11(1):3500. https://doi.org/10.1038/s41467-020-17318-x

PMid:32641730

17. Kluytmans-van den Bergh $M$, Buiting $A G$, Pas $S D$, Bentvelsen RG, van den Bijllaardt W, van Oudheusden AJ, et al. Prevalence and clinical presentation of health care workers with symptoms of Coronavirus disease 2019 in 2 Dutch hospitals during an early phase of the pandemic. JAMA Network Open. 2020;3(5):e209673. https://doi.org/10.1001/ jamanetworkopen.2020.9673

PMid:32437576

18. Lombardi A, Consonni D, Carugno M, Bozzi G, Mangioni D, Muscatello A, et al. Characteristics of 1, 573 healthcare workers who underwent nasopharyngeal swab for SARS-CoV-2 in Milano, Lombardy, Italy. Clin Microbiol Infect. 2020;26(10):1413. e9-13. https://doi.org/10.1016/j.cmi.2020.06.013 PMid:32569835

19. Folgueira MD, Muñoz-Ruipérez C, Alonso-López MA Delgado R. SARS-CoV-2 Infection in Health Care Workers in a Large Public Hospital in Madrid, Spain, During March 2020; 2020. https://doi.org/10.1101/2020.04.07.20055723

20. Tang YW, Schmitz JE, Persing DH, Stratton CW. Laboratory diagnosis of COVID-19: Current issues and challenges. J Clin Microbiol. 2020;58(6):e00512-20. https://doi.org/10.1128/ JCM.00512-20 PMid:32245835

21. He X, Lau EHY, Wu P, Deng $X$, Wang J, Hao $X$, et al. Temporal dynamics in viral shedding and transmissibility of COVID-19. Nat Med. 2020;26(5):672-5. https://doi.org/10.1038/ s41591-020-0869-5 PMid:32296168

22. Yang Y, Yang M, Shen C, Wang F, Yuan J, Li J, et al. Evaluating the accuracy of different respiratory specimens in the laboratory diagnosis and monitoring the viral shedding of 2019-nCoV infections. MedRxiv. 2020;2020:20021493. https://doi. 
org/10.1101/2020.02.11.20021493

23. Martin C, Montesinos I, Dauby N, Gilles C, Dahma H, Van Den Wijngaert $\mathrm{S}$, et al. Dynamics of SARS-CoV-2 RT-PCR positivity and seroprevalence among high-risk healthcare workers and hospital staff. J Hosp Infect. 2020;106(1):102-6. https://doi. org/10.1016/j.jhin.2020.06.028

PMid:32593608

24. Medeiros EA. Health professionals fight against COVID-19. Acta Paul Enferm. 2020;33:eEDT20200003. https://doi. org/10.37689/acta-ape/2020edt0003

25. Paradiso AV, de Summa $S$, Silvestris $N$, Tommasi $S$, Tufaro A, De Palma G, et al. Rapid serological tests have a role in asymptomatic health workers COVID-19 screening. medRxiv. 2020;2020:20057786. https://doi. org/10.1101/2020.04.15.20057786

26. Choe JY, Kim JW, Kwon HH, Hong HL, Jung CY, Jeon CH, et al. Diagnostic performance of immunochromatography assay for rapid detection of $\operatorname{lgM}$ and $\operatorname{lgG}$ in Coronavirus disease 2019. J Med Virol. 2020;92(11):2567-72. https://doi.org/10.1002/ jmv.26060

PMid:32458479

27. Ong DS, de Man SJ, Lindeboom FA, Koeleman JGM. Comparison of diagnostic accuracies of rapid serological tests and ELISA to molecular diagnostics in patients with suspected Coronavirus disease 2019 presenting to the hospital. Clin Microbiol Infect. 2020;26(8):1094.e7-10. https://doi. org/10.1016/j.cmi.2020.05.028 PMid:32502646

28. Zhao J, Yuan Q, Wang H, Liu W, Liao X, Su Y, et al. Antibody responses to SARS-CoV-2 in patients with novel Coronavirus disease 2019. Clin Infect Dis. 2020;71(16):2027-34. https://doi. org/10.1093/cid/ciaa344

PMid:32221519

29. Black J, Bailey C, Przewrocka J, Dijkstra KK, Swanton C. COVID-19: The case for health-care worker screening to prevent hospital transmission. Lancet. 2020;395(10234):1418-20. https://doi.org/10.1016/S0140-6736(20)30917-X PMid:32305073

30. Yang J, Zheng Y, Gou X, Pu K, Chen Z, Guo Q, et al. Prevalence of comorbidities in the novel Wuhan coronavirus (COVID-19) infection: A systematic review and meta-analysis. Int J Infect Dis. 2020;94:91-5. https://doi.org/10.1016/j.ijid.2020.03.017 PMid:32173574

31. Booth CM. Clinical features and short-term outcomes of 144 patients with SARS in the greater Toronto area. JAMA. 2003;289(21):2801-9. https://doi.org/10.1001/jama.289.21. JOC30885

PMid: 12734147

32. Apicella M, Campopiano MC, Mantuano M, Mazoni L, Coppelli A, Del Prato S. COVID-19 in people with diabetes:
Understanding the reasons for worse outcomes. Lancet Diabetes Endocrinol. 2020;8(9):782-92. https://doi.org/10.1016/ S2213-8587(20)30238-2

PMid:32687793

33. Liu S, Zhi Y, Ying S. COVID-19 and asthma: Reflection during the pandemic. Clin Rev Allergy Immunol. 2020;59(1):78-88. https://doi.org/10.1007/s12016-020-08797-3

PMid:32468411

34. Morais-Almeida M, Pité H, Aguiar R, Ansotegui I, Bousquet J. Asthma and the Coronavirus disease 2019 pandemic: A literature review. Int Arch Allergy Immunol. 2020;181(9):680-8. https://doi.org/10.1159/000509057 PMid:32516795

35. Keeley AJ, Evans C, Colton H, Ankcorn M, Cope A, State A, et al. Roll-out of SARS-CoV-2 testing for healthcare workers at a large NHS foundation trust in the United Kingdom, March 2020. Euro Surveill. 2020;25(14):2000433. https://doi.org/10.2807/15607917.ES.2020.25.14.2000433

PMid:32290904

36. Wang D, Hu B, Hu C, Zhu F, Liu X, Zhang J, et al. Clinical characteristics of 138 hospitalized patients with 2019 novel coronavirus-infected pneumonia in Wuhan, China. JAMA. 2020;323(11):1061-9. https://doi.org/10.1001/jama.2020.1585 PMid:32031570

37. D'Amico F, Baumgart DC, Danese S, Peyrin-Biroulet L. Diarrhea during COVID-19 Infection: Pathogenesis, epidemiology, prevention, and management. Clin Gastroenterol Hepatol. 2020;18(8):1663-72. https://doi.org/10.1016/j.cgh.2020.04.001 PMid:32278065

38. WHO. COVID-19 Strategy Update. Geneva: WHO; 2020. Available from: https://www.who.int/docs/defaultsource/coronaviruse/covid-strategy-update-14april2020. pdf?sfvrsn=29da3ba0_19 [Last accessed 2020 Apr 25].

39. Rivett L, Sridhar S, Sparkes D, Routledge M, Jones NK, Forrest $\mathrm{S}$, et al. Screening of healthcare workers for SARSCoV-2 highlights the role of asymptomatic carriage in COVID19 transmission. Elife. 2020;9:e58728. https://doi.org/10.7554/ eLife.58728 PMid:32392129

40. Liu Y, Yan LM, Wan L, Xiang TX, Le A, Liu JM, et al. Vira dynamics in mild and severe cases of COVID-19. Lancet Infect Dis. 2020;20(6):656-7. https://doi.org/10.1016/ S1473-3099(20)30232-2

PMid:32199493

41. Zhou F, Yu T, Du R, Fan G, Liu Y, Liu Z, et al. Clinical course and risk factors for mortality of adult inpatients with COVID-19 in Wuhan, China: A retrospective cohort study. Lancet. 2020;395(10229):1054-62. https://doi.org/10.1016/ S0140-6736(20)30566-3

PMid:32171076 